\title{
Long-Term Multimodal Exercise Program Enhances Mobility of Patients with Parkinson's Disease
}

\author{
Marcelo Pinto Pereira, ${ }^{1}$ Maria Dilailça Trigueiro de Oliveira Ferreira, ${ }^{1}$ \\ Maria Joana Duarte Caetano, ${ }^{1}$ Rodrigo Vitório, ${ }^{1}$ Ellen Lirani-Silva, ${ }^{1}$ \\ Fabio Augusto Barbieri, ${ }^{1}$ Florindo Stella, ${ }^{1,2}$ and Lilian Teresa Bucken Gobbi ${ }^{1}$ \\ ${ }^{1}$ Posture and Gait Studies Laboratory, São Paulo State University at Rio Claro, Avenue 24A, 1515, 13506-900 Rio Claro, SP, Brazil
${ }^{2}$ UNICAMP, University of Campinas, 13083-970 Campinas, SP, Brazil
}

Correspondence should be addressed to Marcelo Pinto Pereira, mppereir@yahoo.com.br

Received 7 August 2012; Accepted 5 September 2012

Academic Editors: J. L. Leasure, K.-H. Lin, and K. Nas

Copyright ( $\odot 2012$ Marcelo Pinto Pereira et al. This is an open access article distributed under the Creative Commons Attribution License, which permits unrestricted use, distribution, and reproduction in any medium, provided the original work is properly cited.

\begin{abstract}
Objective. This study aimed to evaluate the effect of a long-period multimodal exercise program on balance, mobility and clinical status of patients with Parkinson's disease (PD). Methods. Thirty-three PD patients were assigned into two groups: a training group ( TG- $n=22$; aged $67.23 \pm 8.39$ years) and a control group (CG- $n=9$; aged $71.56 \pm 8.50$ years). The TG patients were enrolled in a 6-month multimodal exercise program. This program was designed to improve physical capacity components and to reduce PD impairments. Balance and mobility were assessed immediately before and after the training protocol using the Berg Balance Scale (BBS), the "Timed up and go" (TUG), and the Posture Locomotion Test (PLM). Also, clinical variables were assessed (disease stage and impairments). Results. The TG showed an improvement in the TUG $(P=0.006)$ while CG were not influenced by the 6-months period. Both groups showed no differences for BBS and PLM and for their disease impairments-assessed through the Unified Parkinson's disease Scale. Conclusions. Long-term multimodal exercise programs are able to improve mobility of patients with Parkinson's disease and therefore should be used on clinical day life.
\end{abstract}

\section{Introduction}

Parkinson's disease $(\mathrm{PD})$ is the second neurodegenerative disease in incidence in people over 60 years old [1]. PD patients present a series of non-motor and motor symptoms. However, the motor features, such as bradykinesia, tremor and rigidity are those which mostly decrease their quality of life [2]. As a consequence of these symptoms, PD patients present mobility impairments and lack of balance, which increase their risk of falls (70\% of PD patients fall, at least once within a year [3]). To assess mobility and balance, three different tools had being widely used: the Berg Balance Scale (BBS [4-7]), the "Timed up and Go" test (TUG [8-10]) and the Posture-Locomotor-Manual Test (PLM [11]).

The gold-standard treatment for PD is the pharmacological approach. However, some have shown that the use of such medicines does not fully improve mobility and balance [12]. Actually, the use of some medications for long periods could induce dyskinesia [13], increasing unbalance. Therefore, since exercise has shown to be very successful to improve patients' quality of life, they should be considered [10, 14].

Many specific exercise programs have been suggested to reduce motor impairments of $\mathrm{PD}$ patients, such as walking exercises [15], resistance training [16], constrained-induced movement therapy [17], attention focused exercises [18], and others. The rationale of some of these programs is that patients do not present only the disease impairments, but also suffers the effects of the ageing physiological process. Therefore, they seek to improve specific physical components, as strength. As a result it is expected that the loss of strength presented as an ageing physiological process would be diminished. As consequence, it is believed that patients' limitations would be more related to the disease impairments than to processes linked to ageing process. However, to our understanding this had never been shown. 
TABLE 1: Phases of the proposed long-lasting multimodal program (adapted from Vitório et al. [19]).

\begin{tabular}{|c|c|c|c|}
\hline \multirow{2}{*}{ Phases } & \multicolumn{3}{|c|}{ Capacities } \\
\hline & Coordination & Muscular resistance & Balance \\
\hline Phase 1 & Movements of upper, and lower limbs. & Exercises without weights. & $\begin{array}{l}\text { Recreational activities stimulating } \\
\text { vestibular system }\end{array}$ \\
\hline Phase 2 & $\begin{array}{l}\text { Movements of trunk, upper, and lower } \\
\text { limbs. }\end{array}$ & Exercises with hoops, ropes, and batons. & $\begin{array}{l}\text { Recreational activities stimulating } \\
\text { vestibular system }\end{array}$ \\
\hline Phase 3 & Head movements instead of trunk. & $\begin{array}{l}\text { Exercises with barbells, ankle weights, } \\
\text { and medicine balls. }\end{array}$ & $\begin{array}{l}\text { Stimulation of visual and } \\
\text { somatosensory system }\end{array}$ \\
\hline Phase 4 & $\begin{array}{l}\text { Head, trunk, upper, and lower limb } \\
\text { movements. }\end{array}$ & $\begin{array}{l}\text { Increase of intensity or repetitions } \\
\text { (increased volume). }\end{array}$ & $\begin{array}{l}\text { Integration of vestibular, visual, and } \\
\text { somatosensory systems. }\end{array}$ \\
\hline Phase 5 & $\begin{array}{l}\text { Four different movement sequences: } \\
\text { two with same movements for upper } \\
\text { and lower limbs and two alternating } \\
\text { movements. }\end{array}$ & $\begin{array}{l}\text { Gym exercises: leg press, pulley, seated } \\
\text { cable rows, peck deck, and bench press. } \\
\text { Two series with } 15 \text { repetitions. }\end{array}$ & $\begin{array}{l}\text { Activities including static balance, } \\
\text { dynamic balance, and half-turn and } \\
\text { complete turn (all with visual clues). }\end{array}$ \\
\hline Phase 6 & $\begin{array}{l}\text { Four different movement sequences: } \\
\text { two alternate movements for upper and } \\
\text { lower limbs and two with different } \\
\text { movements. }\end{array}$ & $\begin{array}{l}\text { Increase of load and volume: series of } 15 \\
\text { repetitions were added. }\end{array}$ & Added tactile cues. \\
\hline
\end{tabular}

Most of these exercise programs use short intervention periods (4-12 weeks $[15,16,18])$. These short periods are interesting to improve specific impairments such as flexibility or muscular resistance. However, exercise programs should consider all patients' needs, as the reduction of bradykinesia and rigidity and also the loss of balance. Since PD is a progressive disease, patients also need long exercise programs: it is not expected that symptoms progression would stop after just few weeks of a training program. In this way, the advantages of a multimodal long-lasting training program include: beyond the advantages of specific methods (improvement of strength, flexibility, coordination, etc.) these programs are also focused on patients' motor impairments; they have a high adherence; are feasible; promote an active-life style for more lasting time [10, 19-21]. Indeed our group had already been successful to demonstrate the benefits of long-lasting training program in gait parameters, executive functions, and balance [10, 19-21]. However, the aim of the study of Gobbi et al. [10] (the only one evaluating balance and mobility) was to compare the results of two different training programs (3 times a week versus once a week) and due to the absence of a control group it was not possible to affirm properly that the benefits achieved were determined by the exercise itself.

Therefore, a closer investigation should be conducted to clarify the effect of a long-lasting training program on balance and mobility of PD patients. In this way, the main objective of this study was to evaluate the effect of a 6-months multimode exercise program enrollment in PD patients' dynamic balance, mobility, and clinical status. Also, our objective was to correlate dynamic balance scores to clinical symptoms before and after the exercise program. We hypothesize that after the training program, patients will present maintenance or improvement in balance and mobility and it is believed that balance performance scores will be correlated to clinical outcomes, before and after training.

\section{Materials and Methods}

Thirty-eight participants with mild to moderate idiopathic PD voluntarily participated in this study after signing an informed consent approved by Local Ethics Committee. They were assigned in two groups: a training group (TG; $n=22$ ) and a control group (CG; $n=9$ ). All other major neurological, vestibular, visual, or orthopedics conditions were considered as exclusion criteria. The subjects should be scored between I to III in the Hoehn and Yahr scale [22], not presenting any dementia signal (evaluated by the minimental state examination [23]).

2.1. Intervention. All subjects on $\mathrm{TG}$ were enrolled in a 6-month multimodal exercise program. This program is detailed elsewhere $[10,19,20]$. Briefly, it was developed to a global improvement of PD patients and was composed of exercises that should simultaneously improve all components of functional capacity, such as flexibility (stretching), muscular resistance, motor coordination (rhythmic activities), and balance (recreational motor activities). Also, all exercises were developed relying on patients' symptoms, as bradykinesia, rigid, unbalance, lack of coordination and difficulties to change direction of movement. There is no clarity about the best way to prescribe exercise to PD patients and considering the benefits presented by others on gait and executive functions $[19,20]$, we developed a 6 -months program (24 weeks) composed of 72 sessions, 3 times a week with 60 minutes per session. Each patient should participate in at least $70 \%$ of all sessions to be included in the study. All sessions were conducted in the university facilities with the participation of all subjects at the same time, with supervision of health professionals. To guarantee satisfactory supervision, each four participants were followed by one physiotherapist or physical education professional.

The program involved six phases (Table 1), each one with a total of 12 sessions. Each phase lasted about one month and 
TABLE 2: Subjects characteristics.

\begin{tabular}{lcc}
\hline & Training Group & Control group \\
\hline Age (years) & & \\
$\quad$ Before & $67.23 \pm 8.39$ & $71.56 \pm 8.50$ \\
After & $67.50 \pm 8.36$ & $71.78 \pm 4.20$ \\
Body mass (kg) & & \\
$\quad$ Before & $63.26 \pm 10.28$ & $63.73 \pm 10.72$ \\
$\quad$ After & $69.01 \pm 16.44$ & $69.82 \pm 13.25$ \\
Height (meters) & & \\
$\quad$ Before & $1.61 \pm 0.09$ & $1.55 \pm 0.28$ \\
$\quad$ After & $1.61 \pm 0.15$ & $1.50 \pm 0.37$ \\
UPRDS III (points) & & \\
$\quad$ Before & $21.05 \pm 12.11$ & $33.13 \pm 7.59$ \\
$\quad$ After & $22.00 \pm 13.47$ & $36.56 \pm 7.88$ \\
Hoehn and Yahr (points) & & \\
Before & $1.55 \pm 0.77$ & $1.67 \pm 0.90$ \\
$\quad$ After & $1.64 \pm 0.74$ & $1.72 \pm 0.87$ \\
Disease duration (years) & & \\
$\quad$ Before & $4.55 \pm 4.53$ & $4.63 \pm 3.11$ \\
After & $4.65 \pm 4.33$ & $4.75 \pm 2.92$ \\
Mini-mental (points) & & $24.94 \pm 4.81$ \\
Before & $25.64 \pm 4.04$ & \\
After & $25.70 \pm 3.99$ & $24.56 \pm 4.82$ \\
\hline
\end{tabular}

the workout load was increased at their end. The heart rate (monitored by a heart rate monitor-Polar) was maintained between $60 \%$ and $80 \%$ of maximum heart rate during the main exercises. The main part of each training session lasted 40 minutes and was conducted after warm-up exercises $(\sim 10 \mathrm{~min})$. In this main part of each session the functional capacities were focused. Finally, each session was finished by cool-down activities ( $\sim 10 \mathrm{~min})$. In each session, different functional capacities, such as strength were developed. Two different session examples are given in the Appendices.

The CG did not execute any regular physical activity during the 6-month period. All subjects' regular activities and medication were maintained. Considering ethical principles, the subjects of CG were highly stimulated to keep an active lifestyle during all the study period. However no home-based or other activities were given by the researchers.

2.2. Evaluation. Each participant was evaluated before and after the multimodal program. Firstly, patients were assessed by a neuropsychiatrist to test them on PD motor symptom severity (by means of the motor subsection of the Unified Parkinson's disease Rating Scale (UPDRS-III). The disease severity was assessed by the Hoehn and Yahr scale and the patients' cognitive status by the Mini-Mental State Examination [23].

Also, to assess patients' mobility and balance, they performed three attempts of the TUG $[8,18]$ and PLM [11] tests and were evaluated by the Berg Balance Scale $[4,7]$. Time to complete TUG was considered from the "go" command to the moment that subjects contact their posterior thigh on the chair. The PLM time was recorded from the "go" command to the moment that the object contacts the shelf. On both PLM and TUG, time was achieved by a manual chronometer and free attempts were allowed for familiarization with tasks (2-5 attempts). For BBS, lower scores represent lower balance performance and values below 46 indicate a risk of $40 \%$ for at least one fall episode in the next year [24].

All assessments were conducted on the "on" state of medication (after 1-2 hs of medicine intake).

2.3. Statistical Analyzes. After the normal data distribution analyze (Shapiro-Wilk test), the use of nonparametric tests were necessary, since a high variance was found (explained by different disease aspects). Differences between groups on baseline were assessed by the Mann-Whitney test. To verify the effect of the 6-month multimodal program (before versus after) on clinical and balance (mean of three tasks for TUG and PLM) the Wilcoxon test were used considering the Bonferroni correction. Also, to study the influence of clinical outcomes on balance, a series of Spearman Correlation tests were applied between BBS, PLM, and TUG results with the UPDRS III and Hoehn and Yahr Scale scores. A $P$ value of 0.05 was considered as statistically significant whereas testing differences between groups' baseline scores and 0.025 when testing training effects. All tests were conducted on Statistica 7.0 software for Windows.

\section{Results}

No differences between groups were found on baseline $(P>$ 0.05) for age, body mass, height, UPDRS-III, and Hoehn and Yahr (Table 2). As main results, it can be observed that subjects were on Mild PD stage and presented the disease for a short period.

All subjects on the TG were able to conclude the program with $70 \%$ of presence in all sessions, however, five of them dropped out during the training period due to different reasons. Two of them had moved to another city and three had health complications as stroke, fracture, or a serious decline in general health status. These last three occurrences did not allow the subjects to participate in the rest of the study. No differences on UPRDS-III and disease stage were found for both groups after the 6-months $(Z=0.939, P=$ 0.34 , and $Z=1.605, P=0.108$ for TG; $Z=1.095, P=0.27$, and $Z=2.046, P=0.27$ for $C G)$.

Balance and mobility scores both at before and after are showed on Figures 1 to 3 . No differences were observed between TG and CG for BBS $(Z=1.581, P=0.11-$ Figure 1), TUG $(Z=1.398, P=0.16$-Figure 2$)$, and PLM $(Z=1.913 ; P=0.60$-Figure 3$)$.

However, for TG a positive effect of multimodal training was observed for time to complete the TUG test (Figure 2: $Z=1.489, P=0.006)$, while no differences were observed for CG $(Z=0.140, P=0.88)$. The BBS score remained unchanged for both groups $(Z=1.412, P=0.15$ for TG and $Z=1.095, P=0.27$ for CG) as the PLM test $(Z=1.758$, $P=0.048$ for TG and $Z=0.420, P=0.67)$.

Table 3 presents the correlation coefficients between clinical outcomes and balance before and after the 6-months period. As main result it can be seen that after training 


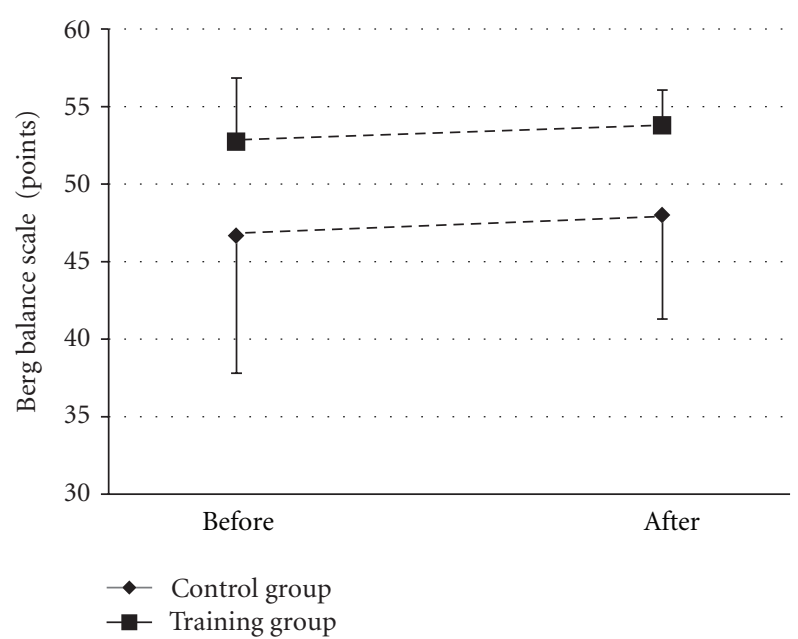

Figure 1: Mean $( \pm$ SD) BBS score for both CG and TG at before and after.

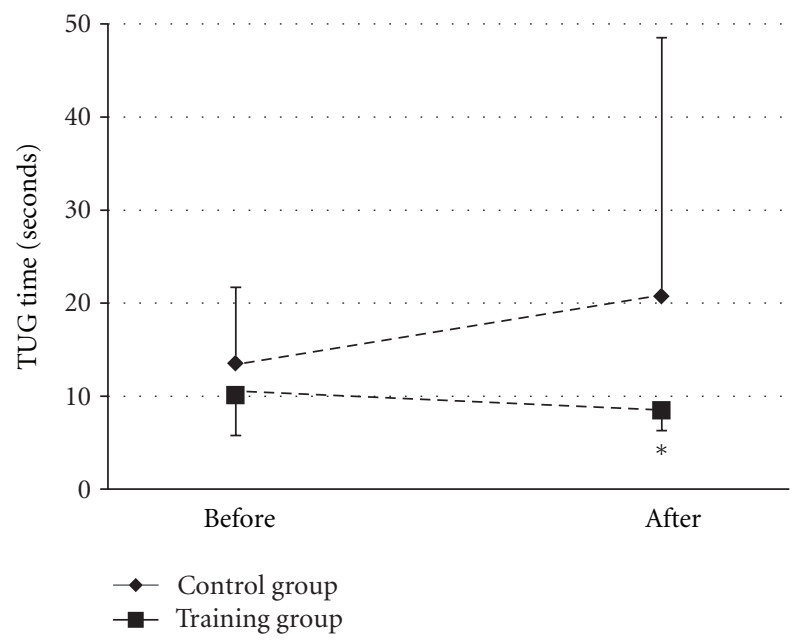

Figure 2: Mean $( \pm S D)$ time to complete TUG for both CG and TG at before and after. ${ }^{*} P<0.05$ to before.

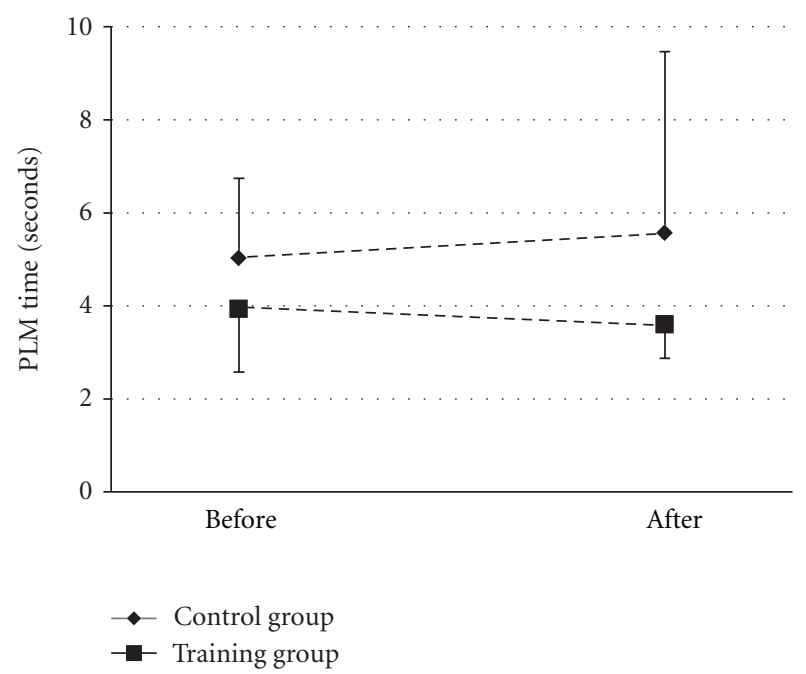

Figure 3: Mean $( \pm$ SD) time to complete PLM for both CG and TG at before and after. ${ }^{*} P<0.05$ to before.
TABLE 3: Correlation coefficients between balance and mobility tests score and disease characteristics.

\begin{tabular}{lcc}
\hline & H\&Y & UPDRS III \\
\hline Training group & & \\
Before & & \\
BBS (points) & $-.529^{*}$ & $-.681^{* *}$ \\
TUG (s) & $.661^{* *}$ & $.580^{* *}$ \\
PLM (s) & $.537^{*}$ & .436 \\
After & & \\
BBS (points) & $-.771^{* *}$ & $-.669^{* *}$ \\
TUG (s) & $.855^{* *}$ & $.758^{* *}$ \\
PLM (s) & $.737^{* *}$ & $.509^{*}$ \\
\hline Control group & & \\
Before & & $0.740^{* *}$ \\
BBS (points) & $-0.820^{*}$ & 0.392 \\
TUG (s) & 0.338 & 0.357 \\
PLM (s) & 0.293 & -0.405 \\
After & & 0.347 \\
BBS (points) & $-0.793^{*}$ & 0.275 \\
TUG (s) & 0.565 & \\
PLM (s) & 0.664 &
\end{tabular}

H\&Y: Hoehn and Yahr Scale; BBS: berg balance scale; TUG: time to up-andgo; PLM: posture locomotors manual.

${ }^{*} P<0.05 ; * * P<0.01$.

the correlation coefficients became stronger for TG. In another way, the same pattern was not observed on CG, showing a null effect of the 6-months period on these coefficients.

\section{Discussion}

The main objective of this study was to investigate the effect of a 6-months multimodal training program in balance and mobility of PD patients and its effects on their disease symptoms. Also, it was an objective to correlate their balance and mobility performance to clinical status before and after this program. As main result we highlight the increase of mobility after the exercise program on TG without any changes for CG and the increase of correlation coefficients between balance and mobility to disease assessments for TG after training. These results show that the proposed long-term multimodal program was successful to reduce physiological aging losses such as strength, flexibility, agility and others.

It is believed that the characteristics of the multimodal training program were responsible for the increased mobility and for the maintenance of balance of our patients. All exercises were based on the patients' impairments, but also were designed to improve their functional capacities. A range of studies have already shown reduction in time to complete TUG after exercise programs using Tai-Chi, Tango dancing, boxing, water-based training, strength, and others [25-30]. However, just few of them had a long-lasting period, ranging from 24-36 weeks [27, 30]. After these programs, a reduction of $12-16 \%$ in time to complete TUG was observed $[27,30]$, values quite low comparing to the $29.8 \%$ found for Huang et al. [31] to be a minimal detectable change for TUG 
in PD patients. In counterpart, our subjects achieved a $30 \%$ reduction in time to complete TUG after the multimodal training program (Figure 2), what could be at least in parts, attributed to the characteristics of our program. We did not compare this multimodal program to other kind of exercises and therefore could not confirm that this program is better than others. However, we can surely state that it is valuable to enhance mobility in initial-mild PD patients.

The results found in the CG, an increase of 7 points supports this statement. Beside the absence of statistical significance, this increase is much greater than that found to be minimaly detectable in PD patients with similar clinical status than ours (stages I-III in Hoehn and Yahr scale) [31]. Indeed, the training effect found on TG was enough to approach the patients' performance to healthy elderly on TUG ( 8.8 to 9.1 seconds [32]). Also, the reduction presented by our subjects were highly superior to that observed on both healthy elderly (8-19.8\% [32-34]). This data is particularly important, since improvement in mobility reduces the risk of falling and therefore, reduces patients' mortality and morbidity [35].

The test and subjects characteristics could explain the lack of significant results after the 6-months period in the BBS score and in time to complete PLM. It is important to observe that our patients presented a high BBS score at baseline, even when compared to healthy elderly [24]. This can be attributed to the initial disease stage, since we found a high correlation between BBS and clinical outcomes (Table 3). Therefore, as patients presented a roof-effect on baseline, it was not expected to observe an important improve on this test after the training period. On the other side, there are few results considering PLM, mainly when PD patients are evaluated and therefore conclusions like that cannot be affirmed properly about this test. However, it is believed that this test is not sensitive enough to detect alterations in PD subjects. Maybe it is not complex enough to evaluate the disease impairments. Further investigations should be conducted about this test and PD.

It is believed that the improvement in mobility was due to increase of performance of physical capacity components [10]. At after, a closer correlation between balance scores and PD severity (Hoehn and Yahr scale) and motor impairments (UPRDS-III) were found (Table 3) in TG. Two hypothesis could be raised to explain this result: (i) the disease advanced in a way that the motor impairments started to play a more important role in the BBS, TUG, and PLM performance; (ii) other features present in older subjects as lower strength, flexibility, coordination, or balance level reduced they role in the tests performance. Since we did not observed a disease advance after the 6-months periods, the second hypothesis seems to be more feasible. We cannot discard the Hawthorne effect, however, since the training program included the development of physical capacity components, as strength, flexibility, coordination, and muscular resistance, we believe that the ageing processes influence over the tests were reduced and therefore, clinical status started to play a more important role. Again, the results of the control group support this hypothesis, since these relations increase was not observed after the 6-months period.
Some study limitations cannot be forgiven, as the low number of subjects, the lack of physical capacity components evaluations and the lack of enrolment of CG in social activities. Also it is important to consider that CG has a lower number of subjects than TG, one point that can influence results, mainly during statistical procedures. This could restrict our results and statements. However, considering the great reduction $(\sim 30 \%)$ in time to complete TUG for TG and the quite increase found it in the CG, we suggest that PD patients should be enrolled on long-lasting physical activity programs where all functional capacity components are worked.

\section{Conclusions}

It can be concluded that the enrollment on a long-lasting multimodal exercise program improves mobility of patients with Parkinson's disease. The use of this kind of exercise program is recommended because of its characteristics: it comprises motivating and exciting exercises that are designed to decrease patients' motor impairments and to develop all physical capacity components.

\section{Appendices}

\section{A. Session 4}

(i) Warm-up and stretching (10 min).

(ii) Balance $(10 \mathrm{~min})$ : each task should be performed 6 times.

Task 1: walk across four different balls placed one in front of other.

Task 2: walk around an arc.

Task 3: climb two backrest steps.

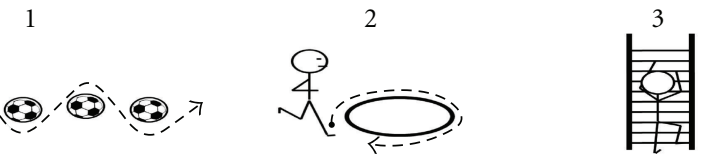

(iii) Strength—main class part (20 min):

(a) Movements (2 series: 40 seconds to 1 minute of resting between series).

(I) Cross the class room in four-points support: 30 seconds without touching the knees to the ground; 30 seconds with knee support.

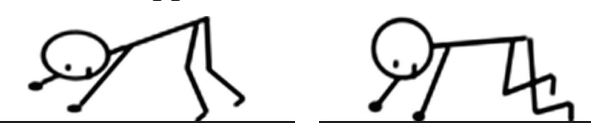

(II) In dorsal position, supporting the body with hands and feet, get the hips off the floor.

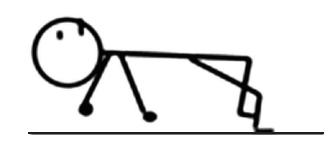


(III) In the same position, however with the upper back touching the ground.

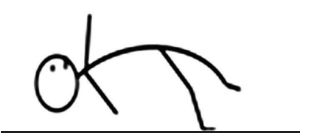

(IV) In the same position, however taking one lower limb off the ground.

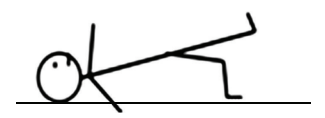

(b) Bicycle Crunch Exercise (two 30-seconds series: 40 seconds to 1 minute of resting period).

(iv) Coordenation (10 min)_Upper limbs movements: hands on shoulders, upper the head, opened arms and straight the body

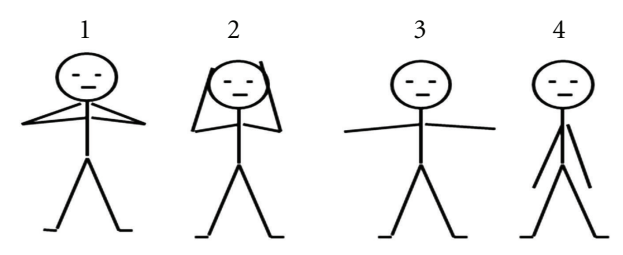

(v) Stretching and relaxing (10 $\mathrm{min})$.

\section{B. Session 72}

(i) Warm-up and stretching (10 min).

(ii) Strength $(10 \mathrm{~min})-3$ series of 30 repetitions each exercise-in a circuit system
(a) Lying Triceps.
(b) Squat.
(c) Tibialis.
(d) Varied Abs.

(iii) Coordination-Main class part (20 min): perform all movements at the same time within exercises.

(I) Kicking with right leg while raising left arm. Repeat with left leg and right arm (4 repetitions).

(II) Abduct right leg and extend left arm. Repeat with left leg and right arm (4 repetitions).

(III) Kicking ahead alternating right and left legs. Start with flexed arms and according to exercise development, patients should open and close their arms while kicking (10 repetitions).

(IV) Abduct right and left legs sequentially while flexing and extending elbows.

(iv) Balance (10 min).

In pairs: while walking around the class room, in a line, the subject should massage the shoulder of partner ahead.

(v) Stretching and relaxing $(10 \mathrm{~min})$.

\section{Acknowledgments}

The authors thank Fundação de Amparo a Pesquisa do Estado de São Paulo (FAPESP) for financial support. All authors disclose any financial relation with any commercial identity mentioned in this paper and state no conflict of interests.

\section{References}

[1] C. W. Olanow, M. B. Stern, and K. Sethi, "The scientific and clinical basis for the treatment of Parkinson disease," Neuro$\log y$, vol. 72, no. 21, supplement 4, pp. S1-S136, 2009.

[2] P. Martínez-Martín, "Impact of the cognitive impairment on the quality of life in patients with Parkinson's disease," Revista de Neurologia, vol. 43, no. 3, pp. 168-172, 2006.

[3] B. R. Bloem, J. M. Hausdorff, J. E. Visser, and N. Giladi, "Falls and freezing of Gait in Parkinson's disease: a review of two interconnected, episodic phenomena," Movement Disorders, vol. 19, no. 8, pp. 871-884, 2004.

[4] P. L. Scalzo, I. C. Nova, M. R. Perracini et al., "Validation of the Brazilian version of the berg balance scale for patients with Parkinson's disease," Arquivos de Neuro-Psiquiatria, vol. 67, no. 3, pp. 831-835, 2009.

[5] A. A. Qutubuddin, P. O. Pegg, D. X. Cifu, R. Brown, S. McNamee, and W. Carne, "Validating the Berg Balance Scale for patients with Parkinson's disease: a key to rehabilitation evaluation," Archives of Physical Medicine and Rehabilitation, vol. 86, no. 4, pp. 789-792, 2005.

[6] D. J. Mayson, D. K. Kiely, S. I. LaRose, and J. F. Bean, "Leg strength or velocity of movement: which is more influential on the balance of mobility limited elders?" American Journal of Physical Medicine and Rehabilitation, vol. 87, no. 12, pp. 969976, 2008.

[7] F. A. Barbieri, N. M. Rinaldi, P. C. Santos et al., "Functional capacity of Brazilian patients with Parkinson's disease (PD): relationship between clinical characteristics and disease severity," Archives of Gerontology and Geriatrics, vol. 54, no. 2, pp. e83-e88, 2011.

[8] B. K. Schilling, R. E. Karlage, M. S. LeDoux, R. F. Pfeiffer, L. W. Weiss, and M. J. Falvo, "Impaired leg extensor strength in individuals with Parkinson disease and relatedness to functional mobility," Parkinsonism and Related Disorders, vol. 15, no. 10, pp. 776-780, 2009.

[9] P. Jayakaran, G. M. Johnson, and S. J. Sullivan, "Reliability and concurrent validity of the step quick turn test in older persons with a unilateral transtibial amputation," American Journal of Physical Medicine \& Rehabilitation, vol. 90, no. 10, pp. 798804, 2011.

[10] L. T. B. Gobbi, M. D. T. Oliveira-Ferreira, M. J. D. Caetano et al., "Exercise programs improve mobility and balance in people with Parkinson's disease," Parkinsonism and Related Disorders, vol. 15, supplement 3, pp. S49-S52, 2009.

[11] S. Hong and B. Steen, "A population-based study on motor performance in elderly men," Korean Journal of Clinical Geriatric, vol. 8, no. 4, 2007.

[12] B. R. Bloem, D. J. Beckley, J. Gert Van Dijk, A. H. Zwinderman, M. P. Remler, and R. A. C. Roos, "Influence of dopaminergic medication on automatic postural responses and balance impairment in Parkinson's disease," Movement Disorders, vol. 11, no. 5, pp. 509-521, 1996.

[13] J. A. Obeso, C. W. Olanow, and J. G. Nutt, "Levodopa motor complications in Parkinson's disease," Trends in Neurosciences, vol. 23, no. 10, supplement, pp. S2-S7, 2000. 
[14] M. A. Hirsch and B. G. Farley, "Exercise and neuroplasticity in persons living with Parkinson's disease," European Journal of Physical and Rehabilitation Medicine, vol. 45, no. 2, pp. 215229, 2009.

[15] Y. R. Yang, Y. Y. Lee, S. J. Cheng, and R. Y. Wang, "Downhill walking training in individuals with parkinson's disease: a randomized controlled trial," American Journal of Physical Medicine and Rehabilitation, vol. 89, no. 9, pp. 706-714, 2010.

[16] T. A. Scandalis, A. Bosak, J. C. Berliner, L. L. Helman, and M. R. Wells, "Resistance training and gait function in patients with Parkinson's disease," American Journal of Physical Medicine \& Rehabilitation, vol. 80, no. 1, pp. 38-43, 2001.

[17] K. S. Lee, W. H. Lee, and S. Hwang, "Modified constraintinduced movement therapy improves fine and gross motor performance of the upper limb in Parkinson disease," American Journal of Physical Medicine and Rehabilitation, vol. 90, no. 5, pp. 380-386, 2011.

[18] M. D. Sage and Q. J. Almeida, "A positive influence of vision on motor symptoms during sensory attention focused exercise for Parkinson's disease," Movement Disorders, vol. 25, no. 1, pp. 64-69, 2010.

[19] R Vitório et al., "Effects of 6-month, multimodal exercise program on clinical and gait parameters of patients with idiopathic Parkinson's disease: a pilot study," ISRN Neurology. In press.

[20] K. Tanaka, A. C. D. Quadros, R. F. Santos, F. Stella, L. T. B. Gobbi, and S. Gobbi, "Benefits of physical exercise on executive functions in older people with Parkinson's disease," Brain and Cognition, vol. 69, no. 2, pp. 435-441, 2009.

[21] L. T. B. Gobbi, "Effects of a multimodal exercise program on clinical, functional mobility and cognitive parameters of idiopathic Parkinson's disease patients," in Parkinson's Disease/ Book 6, A. Lazinica, Ed., InTech, Rijeka, Croatia, 2011.

[22] C. G. Goetz, W. Poewe, O. Rascol et al., "Movement Disorder Society Task Force report on the Hoehn and Yahr staging scale: status and recommendations," Movement Disorders, vol. 19, no. 9, pp. 1020-1028, 2004.

[23] S. M. D. Brucki, R. Nitrin, P. Caramelli, P. H. F. Bertolucci, and I. H. Okamoto, "Suggestions for utilization of the mini-mental state examination in Brazil," Arquivos de Neuro-Psiquiatria, vol. 61, no. 3, pp. 777-781, 2003.

[24] Y. Lajoie and S. P. Gallagher, "Predicting falls within the elderly community: comparison of postural sway, reaction time, the Berg balance scale and the Activities-specific Balance Confidence (ABC) scale for comparing fallers and non-fallers," Archives of Gerontology and Geriatrics, vol. 38, no. 1, pp. 1126, 2004.

[25] J. Vivas, P. Arias, and J. Cudeiro, "Aquatic therapy versus conventional land-based therapy for parkinson's disease: an open-label pilot study," Archives of Physical Medicine and Rehabilitation, vol. 92, no. 8, pp. 1202-1210, 2011.

[26] M. D. Sage and Q. J. Almeida, "Symptom and gait changes after sensory attention focused exercise vs aerobic training in Parkinson's disease," Movement Disorders, vol. 24, no. 8, pp. 1132-1138, 2009.

[27] F. Li et al., "Tai chi and postural stability in patients with Parkinson's disease," The New England Journal of Medicine, vol. 366, no. 6, pp. 511-519, 2012.

[28] M. E. Hackney and G. M. Earhart, "Effects of dance on gait and balance in Parkinsons disease: a comparison of partnered and nonpartnered dance movement," Neurorehabilitation and Neural Repair, vol. 24, no. 4, pp. 384-392, 2010.

[29] M. E. Hackney and G. M. Earhart, "Tai Chi improves balance and mobility in people with Parkinson disease," Gait and Posture, vol. 28, no. 3, pp. 456-460, 2008.
[30] S. A. Combs, D. Diehl, W. H. Staples et al., "Boxing training for patients with parkinson disease: a case series," Physical Therapy, vol. 91, no. 1, pp. 132-142, 2011.

[31] S. L. Huang, C. L. Hsieh, R. M. Wu, C. H. Tai, C. H. Lin, and W. S. Lu, "Minimal detectable change of the timed "up \& go" test and the dynamic gait index in people with parkinson disease," Physical Therapy, vol. 91, no. 1, pp. 114-121, 2011.

[32] F. M. Alfieri, M. Riberto, L. S. Gatz et al., "Functional mobility and balance in community-dwelling elderly submitted to multisensory versus strength exercises," Clinical Interventions in Aging, vol. 5, pp. 181-185, 2010.

[33] T. Tsourlou, A. Benik, K. Dipla, A. Zafeiridis, and S. Kellis, "The effects of a twenty-four-week aquatic training program on muscular strength performance in healthy elderly women," Journal of Strength and Conditioning Research, vol. 20, no. 4, pp. 811-818, 2006.

[34] T. Arai, S. Obuchi, Y. Inaba, Y. Shiba, and K. Satake, "The relationship between physical condition and change in balance functions on exercise intervention and 12-month follow-up in Japanese community-dwelling older people," Archives of Gerontology and Geriatrics, vol. 48, no. 1, pp. 61-66, 2009.

[35] H. J. Lee and L. S. Chou, "Detection of gait instability using the center of mass and center of pressure inclination angles," Archives of Physical Medicine and Rehabilitation, vol. 87, no. 4, pp. 569-575, 2006. 


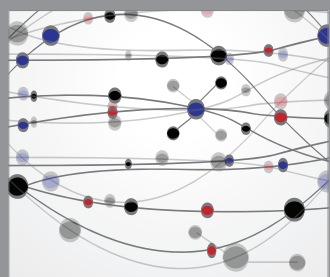

The Scientific World Journal
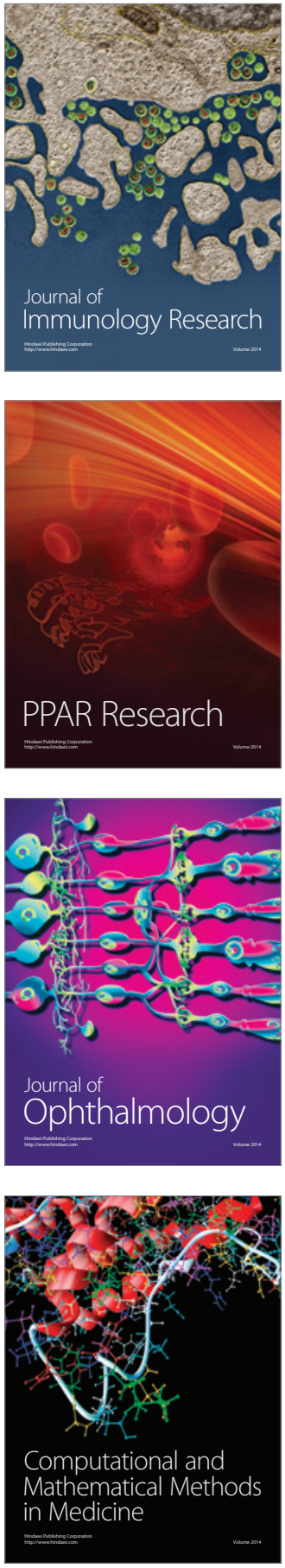

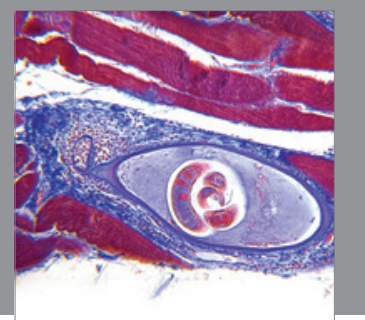

Gastroenterology

Research and Practice
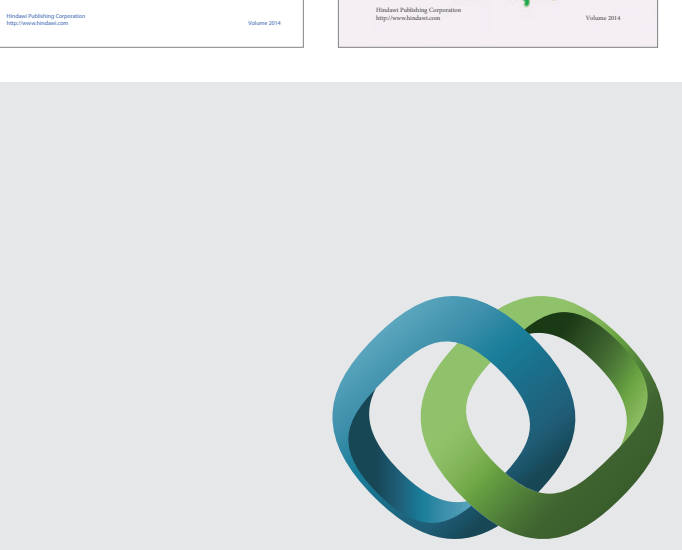

\section{Hindawi}

Submit your manuscripts at

http://www.hindawi.com
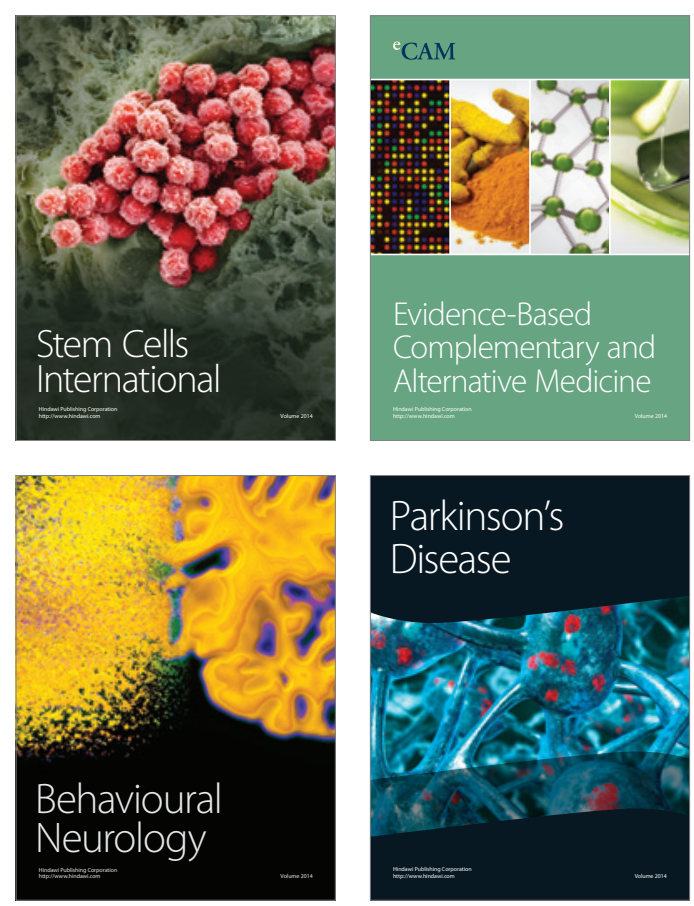

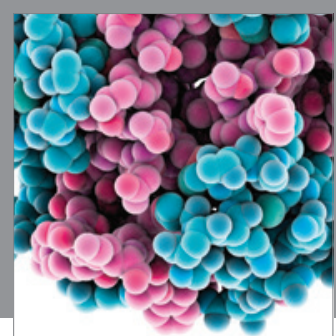

Journal of
Diabetes Research

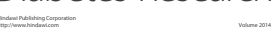

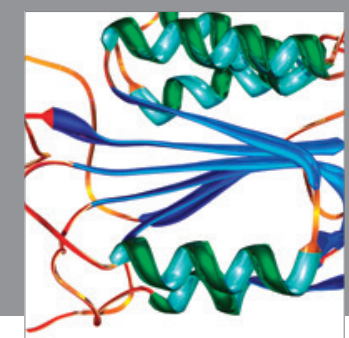

Disease Markers
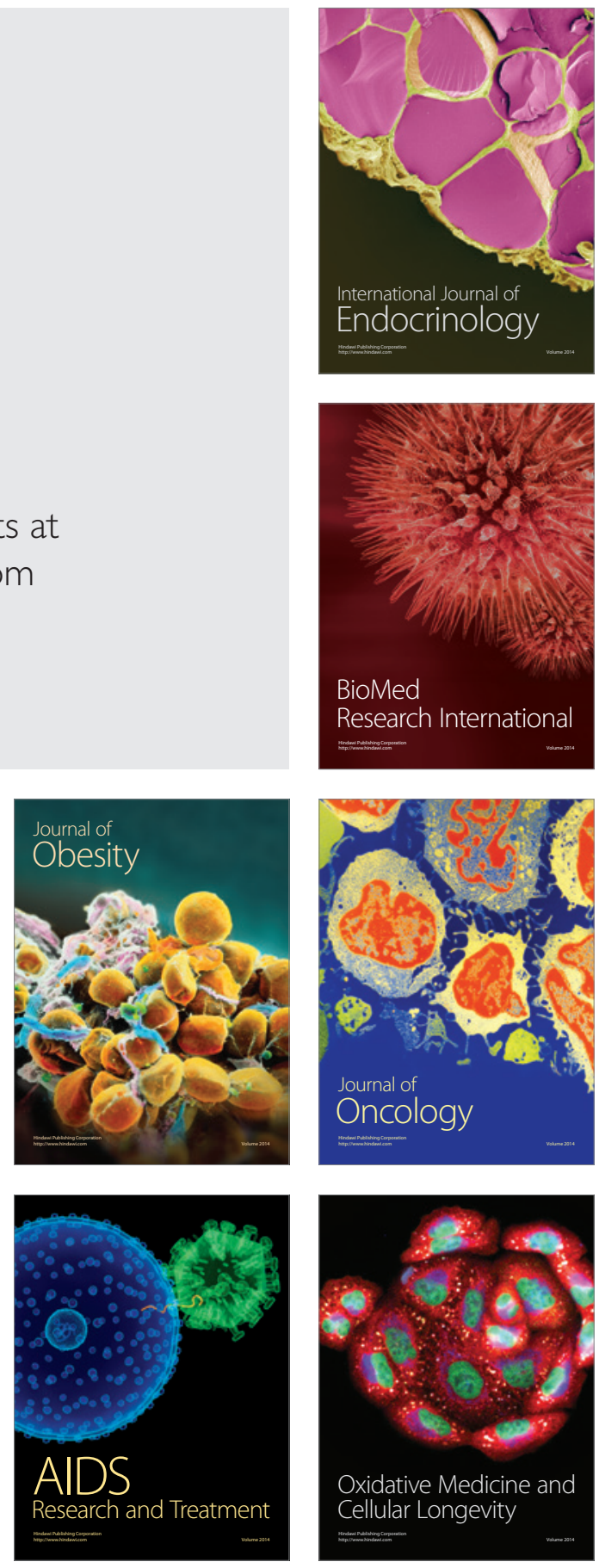